\title{
When and How Should Infant Industries Be Protected?
}

\section{Citation}

Melitz, Marc J. 2005. When and how should infant industries be protected?. Journal of International Economics 66, no. 1: 177-196.

\section{Published Version}

http://dx.doi.org/10.1016/j.jinteco.2004.07.001

\section{Permanent link}

http://nrs.harvard.edu/urn-3:HUL.InstRepos:3228378

\section{Terms of Use}

This article was downloaded from Harvard University's DASH repository, and is made available under the terms and conditions applicable to Other Posted Material, as set forth at http:// nrs.harvard.edu/urn-3:HUL.InstRepos:dash.current.terms-of-use\#LAA

\section{Share Your Story}

The Harvard community has made this article openly available.

Please share how this access benefits you. Submit a story.

\section{Accessibility}




\title{
When and How Should Infant Industries Be Protected?
}

\author{
Marc J. Melitz* \\ Harvard University \\ NBER \\ and \\ CEPR
}

Revised: May 14, 2003

\begin{abstract}
This paper develops and analyzes a welfare maximizing model of infant industry protection. The domestic infant industry is competitive and experiences dynamic learning effects that are external to firms. The competitive foreign industry is mature and produces a good that is an imperfect substitute for the domestic good. A government planner can protect the infant industry using domestic production subsidies, tariffs, or quotas in order to maximize domestic welfare over time. As protection is not always optimal (even though the domestic industry experiences a learning externality), the paper shows how the decision to protect the industry should depend on the industry's learning potential, the shape of the learning curve, and the degree of substitutability between domestic and foreign goods.

Assuming some reasonable restrictions on the flexibility over time of the policy instruments, the paper subsequently compares the effectiveness of the different instruments. Given such restrictions, the paper shows that quotas induce higher welfare levels than tariffs. In some cases, the dominance of the quota is so pronounced that it compensates for any amount of government revenue loss related to the administration of the quota (inclusing the case of a voluntary export restraint, where no revenue is collected). In similar cases, the quota may even be preferred to a domestic production subsidy.
\end{abstract}

${ }^{*}$ Department of Economics, Littauer Center, Harvard University, Cambridge, MA 02138 or mmelitz@harvard.edu. The author thanks Alan Deardorff, Jim Levinsohn, and the editor, Rob Feenstra, for many helpful comments and suggestions (the usual disclaimer applies). 


\section{Introduction}

The infant industry argument is one of the oldest arguments used to justify the protection of industries from international trade. First formulated by Alexander Hamilton and Friedrich List at the beginning of the Nineteenth Century, the case for infant industry protection has been generally accepted by economists over the last two centuries - although some of the arguments supporting protection have come under successful attacks over the years. In his famous statement supporting the case for infant industry protection, John Stuart Mill alluded to one of the main pre-requisites for such industries: the presence of dynamic learning effects that are external to firms. ${ }^{1}$ Mill recognized that certain additional conditions must also be met in order to justify protection. He specifically mentioned that protection must be temporary and that the infant industry must then mature and become viable without protection. Subsequently, Charles Francis Bastable added another condition requiring that the cumulative net benefits provided by the protected industry exceed the cumulative costs of protection. ${ }^{2}$ Together, these conditions are known as the Mill-Bastable Test. The economics literature has subsequently developed formal models with dynamic learning externalities demonstrating how protection can potentially raise welfare. This literature has also shown that the protection provided by production subsidies is preferable to that provided by tariffs or quotas, as the latter additionally distort consumption. Nevertheless, production subsidies may not be feasible due to government fiscal constraints and distortions associated with raising the needed revenue.

Now consider the problems encountered by a government planner who wishes to follow these relatively straightforward recommendations when deciding on a specific policy for an infant industry characterized by the previously mentioned learning effects. Though clear and intuitive, the Mill-Bastable Test is hard to apply in practice: both the benefits and costs of protection change over time as learning progresses. The cumulative benefits and costs not only reflect the changes driven by the learning process but also those caused by the adjustment over time of the level of protection (typically, the latter decreases as learning progresses). Recommendations for the policy instrument choice (subsidy, tariff, or quota) are equally clear but also greatly complicated by practical considerations. The recommendations are based on the assumption that the level of the policy instrument can be costlessly changed over time. In fact, these changes are costly and may

\footnotetext{
${ }^{1}$ See Mill (1848, pp. 918-19). The full statement is re-printed in Kemp (1960).

${ }^{2}$ See Bastable (1891, pp. 140-143). For further discussion of the Mill-Bastable Test, see Kemp (1960) and Corden (1997, ch. 8).
} 
not even be feasible over certain time intervals. ${ }^{3}$ How do these considerations affect the government planner's choice of policy instrument?

This paper seeks to answer this question and assist the government planner with the application of the Mill-Bastable Test. The paper shows how the cumulative costs of protection can be approximated by a fixed learning cost that can be readily compared to an appropriately normalized benefit flow. The paper describes how the fulfillment of the test depends on the industry's learning potential, the speed of learning, and the degree of substitutability between the domestic and foreign goods. When the test has been met, the paper then shows how the presence of adjustment costs and uncertainty concerning the learning curve confer an advantage to the quota over the other two policy instruments. In particular, the quota will almost always yield higher welfare outcomes than the tariff. In some cases, the dominance of the quota is so pronounced that it compensates for any amount of government revenue loss related to the administration of the quota. (This is true even in the extreme case of a voluntary export restraint (VER), when no revenue is collected.) It is further shown that the quota may even be preferred to domestic production subsidies. Briefly, the advantage of the quota vis-a-vis the subsidy or tariff is that its level of protection automatically declines as learning progresses (a desired property for welfare maximization). On the other hand, the tariff and subsidy must be adjusted downward to produce this effect. This adjustment requires additional information about the pace of learning (which may not be known with certainty) and may be costly or even infeasible.

Other recent work has also challenged the view that necessarily attributes the use of quantity restrictions (which is widespread) to non-welfare-maximizing behavior by governments. ${ }^{4}$ This work has shown how some relevant considerations affecting the implementation of trade policies can lead welfare maximizing governments to choose quantity restrictions. Feenstra and Lewis (1991) show that VERs are negotiated by governments in order to credibly signal the level of domestic political pressure to their trading partner. Anderson and Schmitt (2003) show that governments may resort to quotas after having cooperatively negotiated tariff levels. Finally, Bagwell and Staiger (1990) show that trade policies involving quantity restrictions may allow non-cooperative governments to enforce trade agreements over the business cycle. The current paper seeks to complement this work by providing another realistic example where welfare maximizing governments may choose quantity

\footnotetext{
${ }^{3}$ The cost or incapacity to adjust the policy instrument may be driven by actual costs and political procedures or alternatively by the capture of the political process (once the policy is implemented) by special interest groups.

${ }^{4}$ These models are reviewed in Deardorff (1987). Political economy models that explain the use of trade policies as a voting or lobbying equilibrium also fall within this category.
} 
restrictions over other trade policy instruments.

\section{Learning-by-Doing and Infant Industry Protection}

I assume that the infant industry's dynamic learning occurs through learning-by-doing. The infant industry argument based on this type of learning externality was first explicitly modeled in a dynamic framework by Bardhan (1971). His single industry model has since been extended to analyze the consequences of learning in more than one industry. Clemhout and Wan (1970) study infant industry protection policies for a group of industries that experience different rates of learning. Succar (1987) and Young (1991) examine the impact of learning spillovers across industries. Krugman (1987) further extends the multi-industry model by allowing for learning in both the home and foreign industries. This last treatment departs from the assumption that a particular country is less developed than its trading partners and rather focuses on the study of the pattern of trade when comparative advantage is dynamic. His model does relate to infant industry protection, as he describes how a country can expand the set of industries in which it has a static comparative advantage through the use of trade policies. Redding (1999) incorporates welfare analysis in this type of model and explicitly shows how protection can enhance welfare through such a mechanism.

This paper returns to Bardhan's (1971) single industry framework but relaxes the assumption that the domestic and foreign goods are perfect substitutes - introducing Armington product differentiation. Consumers thus derive some benefit from consuming both the domestic and foreign variety. This paper further extends his work by considering several different types of trade instruments when these are not perfectly flexible over time (Bardhan (1971) only considers the use of flexible production subsidies). Learning is assumed to be bounded, thereby eliminating any motive for permanent protection. Although temporary protection may be warranted, this will not always be the welfare maximizing policy as I explicitly consider cases where the Mill-Bastable Test is not passed; I then show how the characteristics of the industry influence the fulfillment of this test. ${ }^{5}$

\footnotetext{
${ }^{5}$ Head (1994) and Irwin (2000) use a similar theoretical structure to empirically measure the cumulative costs and benefits of two particular instances of infant industry protection.
} 


\section{The Model}

\section{Learning and Production}

The domestic and foreign goods are homogeneous, and produced by competitive firms in both countries. The technologies used by all firms exhibit static constant returns to scale. However, the domestic industry is in its "infant" phase where its marginal cost at time $t, c_{t}$, decreases with cumulative production $Q_{t}=\int_{0}^{t} q_{s} d s$ as the industry is learning-by-doing. Time is continuous and $q_{t}$ represents represents total domestic production at time $t$. Learning is bounded, and the domestic industry becomes mature after a threshold level of cumulative production $\bar{Q}$ is attained. The marginal production cost then no longer varies with cumulative production and remains at its long-run level $\bar{c}$. Specifically, learning is characterized by a function $c_{t}=c\left(Q_{t}\right)$ with the following properties:

$$
\begin{cases}c\left(Q_{0}\right)=c_{0}>\bar{c} & \left(Q_{0}=0\right), \\ c^{\prime}\left(Q_{t}\right)<0 & \forall Q_{t}<\bar{Q}, \\ c\left(Q_{t}\right)=\bar{c} & \forall Q_{t} \geq \bar{Q} .\end{cases}
$$

This learning function is assumed to be differentiable everywhere, though its shape is not further restricted. The foreign technology has matured at a marginal cost level $\tilde{c}$, which remains constant over time. ${ }^{6}$ The relative levels of the long run costs $\bar{c}$ and $\tilde{c}$ are left unrestricted. The learning externality arises from the competitive nature of the industry and the technological spillovers: domestic firms assume that the effect of their own production on industry output is negligible and thus do not internalize the future cost-reducing effects of their current production. Each firm thus myopically values its output at its current marginal cost $c_{t}$.

In order to simplify the ensuing analysis, a rather extreme form of spillovers and externality has been assumed: spillovers between domestic firms are complete, ${ }^{7}$ whereas international spillovers are non-existent; firms then do not internalize any of the future benefits of their current production. These assumptions are intended as a simplification of an environment where intra-national spillovers dominate international ones ${ }^{8}$ and firms do not fully internalize the benefits of their current production on future costs.

\footnotetext{
${ }^{6}$ Throughout this paper, tildes ( ) will be used to denote foreign variables.

${ }^{7}$ See Dasgupta and Stiglitz (1988) for a discussion of the effects of incomplete versus complete spillovers.

${ }^{8}$ Branstetter (2001) finds very strong support for this assumption based on spillovers within and between U.S. and Japanese firms.
} 


\section{Domestic Demand}

Domestic demand is generated by a representative consumer whose instantaneous utility function is additively separable in a numeraire good. The instantaneous utility gained from the aggregate consumption of the domestic $(q)$ and foreign $(\tilde{q})$ goods is represented by a strictly concave utility function $U(q, \tilde{q})$. Let $U_{q}(q, \tilde{q})$ and $U_{\tilde{q}}(q, \tilde{q})$ denote the first derivatives and $U_{q q}(q, \tilde{q}), U_{\tilde{q} \tilde{q}}(q, \tilde{q}), U_{q \tilde{q}}(q, \tilde{q})$ denote the second and cross-partial derivatives of this utility function. ${ }^{9}$ In order to make the analysis of the Mill-Bastable Test relevant, domestic consumers should be able to forego consumption of the domestic good in favor of the sole consumption of the foreign variety. The marginal utility of the domestic good, $U_{q}(q, \tilde{q})$, is therefore assumed to admit a finite upper bound. ${ }^{10}$ Given prices $p$ and $\tilde{p}$, the representative consumer chooses quantities $q$ and $\tilde{q}$ that maximize consumer surplus $C S=U(q, \tilde{q})-p q-\tilde{p} \tilde{q}$. This yields a demand system $[q(p, \tilde{p}), \tilde{q}(p, \tilde{p})]$ where $\partial q(p, \tilde{p}) / \partial p$ and $\partial \tilde{q}(p, \tilde{p}) / \partial \tilde{p}$ are negative (by concavity of $U(q, \tilde{q}))$ and $\partial q(p, \tilde{p}) / \partial \tilde{p}$ and $\partial \tilde{q}(p, \tilde{p}) / \partial p$ are non-negative (since the two goods are substitutes).

The assumption of bounded marginal utility for $q$ further implies the existence of "choke" prices beyond which demand for the domestic good is driven to zero: given any foreign price $\tilde{p}$, there exists a choke price $p^{0}$ for the domestic good such that $q(p, \tilde{p})=0$ for all $p \geq p^{0}$. Since the two goods are substitutes, this choke price $p^{0}$ must be a non-decreasing function of $\tilde{p}$. Whenever demand for the domestic good is zero, demand for the foreign good will be uniquely determined by its price $\tilde{p}$. Let $\bar{q}=q(\bar{c}, \tilde{c})$ and $\overline{\tilde{q}}=\tilde{q}(\bar{c}, \tilde{c})$ denote the long run demand levels under free trade (after learning is complete). Both demand levels are assumed positive. On the other hand, the initial demand for the domestic good under free trade, $q_{0}=q\left(c_{0}, \tilde{c}\right)$, could be zero. Without any policy intervention, domestic production would then not occur and only the foreign variety would be consumed. Let $\tilde{q}^{0}=\tilde{q}\left(c_{0}, \tilde{c}\right)$ denote this constant foreign demand level.

In order to simplify some of the ensuing analysis pertaining to tariffs and quotas (where the exact form of substitution between the domestic and foreign goods becomes relevant), this paper will use a simple linear parametrization of the demand system. This demand structure is generated by a symmetric quadratic utility function $U(q, \tilde{q})$ with constant second and cross-partial derivatives. ${ }^{11} \beta \equiv-U_{q q}(q, \tilde{q})=-U_{\tilde{q} \tilde{q}}(q, \tilde{q})>0$ then indexes the slope of the demand curves while

\footnotetext{
${ }^{9} U_{q \tilde{q}}(q, \tilde{q}) \leq 0$ since the goods are substitutes.

${ }^{10}$ The marginal utility of the foreign good may also be bounded, although this will not be relevant for the analysis.

${ }^{11}$ Symmetry is only introduced in order to nest perfect substitution between the goods as a special limiting case. Note that the symmetry of $U(.,$.$) still allows for quality differences between the goods through specification of their$ quantity units (and possibly their costs).
} 
$\eta \equiv-U_{q \tilde{q}}(q, \tilde{q}) / \beta \in[0,1]$ captures the substitutability (or inverse level of product differentiation) between the two goods. Product substitutability increases with $\eta$ from zero (the demand for the two goods are unrelated) to one (the goods are perfect substitutes).

\section{Domestic Welfare and Policies}

A government planner may use domestic production subsidies, tariffs, or quotas to "protect" the domestic infant industry. The usage of these instruments may potentially be restricted (as will be described in more detail later). Exports by the domestic industry in its infant phase are assumed to be negligible. ${ }^{12}$ At any time $t$, a quota is equivalent to a particular tariff level (for now the quota rights are assumed to be auctioned and collected by the government). Given the competitive market structure, a time $t$ subsidy $\sigma_{t}$ and tariff $\tau_{t}$ affect domestic prices in the following way: $p_{t}=c_{t}-\sigma_{t}, \tilde{p}_{t}=\tilde{c}+\tau_{t}$. Since learning is only modeled in its reduced form, as incorporated in cumulative production, I only consider trade policies that directly affect the production level of the firms. As pointed out by Baldwin (1969), trade policies directed at the source of the externality (knowledge creation and dissemination) should be considered. This would involve a more structural approach to the learning process and is beyond the scope of this paper.

The policy choices lead to domestic demand levels $q_{t}=q\left(p_{t}, \tilde{p}_{t}\right)$ and $\tilde{q}_{t}=\tilde{q}\left(p_{t}, \tilde{p}_{t}\right)$, and domestic welfare $W_{t}=C S_{t}-\sigma_{t} q_{t}-\tau_{t} \tilde{q}_{t}=U\left(q_{t}, \tilde{q}_{t}\right)-c_{t} q_{t}-\tilde{c} \tilde{q}_{t}$. The government planner is benevolent and chooses policies to maximize the discounted sum of welfare flows over a given period of time $T$ that always includes the entire learning phase (so long as domestic production occurs). ${ }^{13}$ As pointed out by Dixit (Supplement 1984), the planner's choice of instruments can be re-interpreted as a choice of consumption quantities from a feasible set generated by the consumer's demand. Any restrictions on trade instruments would then be transformed into additional restrictions on the set of feasible consumption pairs. The planner's problem can thus be written as:

$$
\max _{\left(q_{t}, \tilde{q}_{t}\right) \in \mathcal{F}_{t}} T W=\int_{0}^{T} e^{-\rho t} W_{t} d t=\int_{0}^{T} e^{-\rho t}\left[U\left(q_{t}, \tilde{q}_{t}\right)-c_{t} q_{t}-\tilde{c} \tilde{q}_{t}\right] d t
$$

where $\mathcal{F}_{t} \subseteq \Re_{+}^{2}$ is the set of feasible quantity pairs at time $t$ and $\rho$ is the exogenous discount rate. The planning period of length $T$ is used instead of an infinite horizon in order to allow for the simplification of negligible discounting $(\rho=0)$ during the learning phase. Since these learning

\footnotetext{
${ }^{12}$ This precludes the use of export subsidies to accelerate the learning process.

${ }^{13}$ The planner may also care about domestic welfare after time $T$, though the optimal policies at that time must be free trade (no protection).
} 
phases are reasonably short (on the order of years, not decades) the formal modeling of low discount factors is fairly inconsequential. In order to avoid uninteresting case, the chosen policies are assumed to always lead to positive demand for the foreign good. However, the possibility of zero demand for the domestic good (when initial costs are high) will lead to some interesting scenarios that will be explicitly analyzed.

\section{No Intervention Benchmark}

When no policy instruments are used, two general cases will arise: i) If the initial domestic cost $c_{0}$ is high enough to preclude demand for the domestic good under free trade $\left(q\left(c_{0}, \tilde{c}\right)=0\right)$, then the domestic industry will not "survive" (there will be no domestic production) - regardless of its learning potential. Consumers solely rely on imports $\tilde{q}^{0}=\tilde{q}\left(c_{0}, \tilde{c}\right)$ of the foreign variety. ii) If $c_{0}$ is low enough $\left(q\left(c_{0}, \tilde{c}\right)>0\right)$, then domestic production occurs and increases over time as learning progresses. Imports of the foreign variety $\tilde{q}_{t}$ simultaneously decrease during this phase. Demand levels stabilize at their long run levels $\bar{q}$ and $\overline{\tilde{q}}$ after learning ceases.

\section{Flexible Trade Policies}

In this section, I assume that the government planner can choose any time paths for the subsidies and tariffs over the planning horizon from $t=0$ to $t=T$. This assumption defines the set $\mathcal{F}_{t}$ of possible output pairs $\left(q_{t}, \tilde{q}_{t}\right)$. The social planner thus solves the maximization problem (1) subject

to the conditions $c_{t}=c\left(Q_{t}\right), q_{t}=\dot{Q}_{t}$ (no exports of the domestic good) and the initial boundary condition $Q_{0}=0\left(Q_{T}\right.$ is left unrestricted). Let $\mathcal{H}$ be the current value Hamiltonian associated with this problem:

$$
\mathcal{H}\left(q_{t}, \tilde{q}_{t}, Q_{t}\right)=U\left(q_{t}, \tilde{q}_{t}\right)-c\left(Q_{t}\right) q_{t}-\tilde{c} \tilde{q}_{t}+\lambda_{t} q_{t}
$$

where $\lambda_{t} \geq 0$ is the current value shadow price of a unit of cumulative production. 


\section{Interior Solution: Positive Domestic Production Levels}

Assuming $q_{t}>0$ and $\tilde{q}_{t}>0$, the first order conditions for the planner's problem are given by:

$$
\begin{aligned}
\frac{\partial \mathcal{H}}{\partial q_{t}} & =U_{q}\left(q_{t}, \tilde{q}_{t}\right)-c\left(Q_{t}\right)+\lambda_{t}=0, \\
\frac{\partial \mathcal{H}}{\partial \tilde{q}_{t}} & =U_{\tilde{q}}\left(q f, \tilde{q}_{t}\right)-\tilde{c}=0, \\
\frac{\partial \mathcal{H}}{\partial Q_{t}} & =-c^{\prime}\left(Q_{t}\right) q_{t}=\rho \lambda_{t}-\dot{\lambda}_{t} .
\end{aligned}
$$

Since $Q_{T}$ is left unrestricted, the transversality condition yields $\lambda_{T}=0$. Conditions (2) and (3) imply $\tau_{t}=0$ and $\sigma_{t}=\lambda_{t}$ : along the optimal interior path, no tariffs should be used and the subsidy in any period should be equal to the current value of a unit of learning.

Condition (4) gives an equation of motion for domestic output. Using (2) and (3), $\tilde{q}_{t}, \lambda_{t}$, and $\dot{\lambda}_{t}$ can be written as functions of $Q_{t}, q_{t}$, and $\dot{q}_{t}$, yielding a second order differential equation for $Q_{t}$. Integrating (4) yields an expression for the optimal subsidy as a function of current and future domestic costs:

$$
\sigma_{t}=c_{t}-e^{-\rho(T-t)} c_{T}-\rho \int_{t}^{T} e^{-\rho(s-t)} c_{s} d s .
$$

Learning ceases at some (endogenously determined) point $\bar{t}$ during the planning period; thereafter, $c_{t}$ is constant at $\bar{c}$. Since future $\operatorname{costs} c_{s}$ will be bounded between current costs and the long run $\operatorname{cost}\left(\bar{c} \leq c_{s} \leq c_{t}\right),(5)$ can be used to obtain bounds on the optimal subsidy and domestic price:

$$
\begin{gathered}
e^{-\rho(\bar{t}-t)}\left(c_{t}-\bar{c}\right) \leq \lambda_{t} \leq c_{t}-\bar{c} \\
\bar{c} \leq p_{t} \leq e^{-\rho(\bar{t}-t)} \bar{c}+\left(1-e^{-\rho(\bar{t}-t)}\right) c_{t} .
\end{gathered}
$$

As long as there is learning potential $\left(c_{t}>\bar{c}\right)$, positive subsidies should be used although they should never be greater than the current learning potential measured as the difference between current and long run costs $c_{t}-\bar{c}$. Of course, subsidies should cease with learning at $\bar{t}$. The upper bound on the current price $p_{t}$ is a weighted average of the current and long run $\operatorname{costs} c_{t}$ and $\bar{c}$. Given a reasonable discount factor and learning period length, the weight on $\bar{c}$ will dominate that on $c_{t} \cdot{ }^{14}$ When the discount rate is negligible $(\rho=0)$, the domestic price $p_{t}$ should remain constant at $\bar{c}$, which is then the constant social marginal cost of a unit of domestic production. Subsidies

\footnotetext{
${ }^{14} \mathrm{~A}$ discount factor under $4 \%$ and learning period of up to 5 years lead to a weight on $\bar{c}$ that is more than 4 times higher than the weight on $c_{t}$.
} 
at any time $t$ are then given by the learning potential $c_{t}-\bar{c}$. These subsidies decrease over time, regardless of the shape of the learning curve. Under these scenarios, domestic output and foreign imports remain constant at their long run free trade levels $\bar{q}$ and $\overline{\tilde{q}}$. Given the flexibility of the trade instruments, the feasibility of these consumptions paths is guaranteed.

\section{Corner Solution: No Domestic Production}

If domestic production is zero at any point along the optimal path, then it must be zero over the entire optimal path. ${ }^{15}$ Given this, the first order conditions for the planner's problem only require that the marginal utility of the foreign good be equated to its cost (again, no tariff should be used) and that the shadow value of cumulative production be zero: no subsidies are then used. This scenario is feasible only when no intervention leads to zero demand for the domestic good. Initial costs $c_{0}$ must be high enough that $q\left(c_{0}, \tilde{c}\right)=0$. Otherwise, domestic production would be positive, and the interior optimal path must be followed.

\section{The Mill-Bastable Test}

The previous analysis revealed that, under some conditions on the initial costs, there are two scenarios satisfying the first order conditions for welfare maximization: production subsidies (satisfying the interior solution path) and laissez-faire (no domestic industry and reliance on imports). The social planner must then determine which solution yields higher total welfare. This amounts to applying the Mill-Bastable Test.

The evaluation of different trade policies depends on the comparisons of the welfare flows $W_{t}$ induced by the trade policies. Unfortunately, these flows are hard to compare because they are not only a function of the consumption levels $\left(q_{t}, \tilde{q}_{t}\right)$ but also critically depend on the current level of domestic cost $c_{t}$. This section shows how cumulative total welfare $T W$ can be decomposed into a sum of welfare flows that do not depend on the changing current domestic cost and a separate fixed learning cost. For simplicity, the following derivations assume that the effects of discounting are negligible. ${ }^{16}$ Given this assumption, any pair of consumption paths $\left(q_{t}, \tilde{q}_{t}\right)$ that induce learning

\footnotetext{
${ }^{15}$ When the domestic good is consumed, its consumption path must be non-decreasing. Thus, if consumption of the domestic good is positive at any time $t$, it must also be positive at any time after $t$. Furthermore, it can not be optimal to start domestic production at time $t>0$ since the same consumption path pushed back to start at $t=0$ would yield higher welfare.

${ }^{16}$ The formal modeling of a small discount rate does not qualitatively change any of the results. A separate appendix describes in more detail how discounting will affect the following analysis. Briefly, the discount rate should be small enough such that the effects of discounting during the learning period are dominated by the learning effects. The effects of discounting after learning has occurred may be significant if the planning period extends significantly
} 

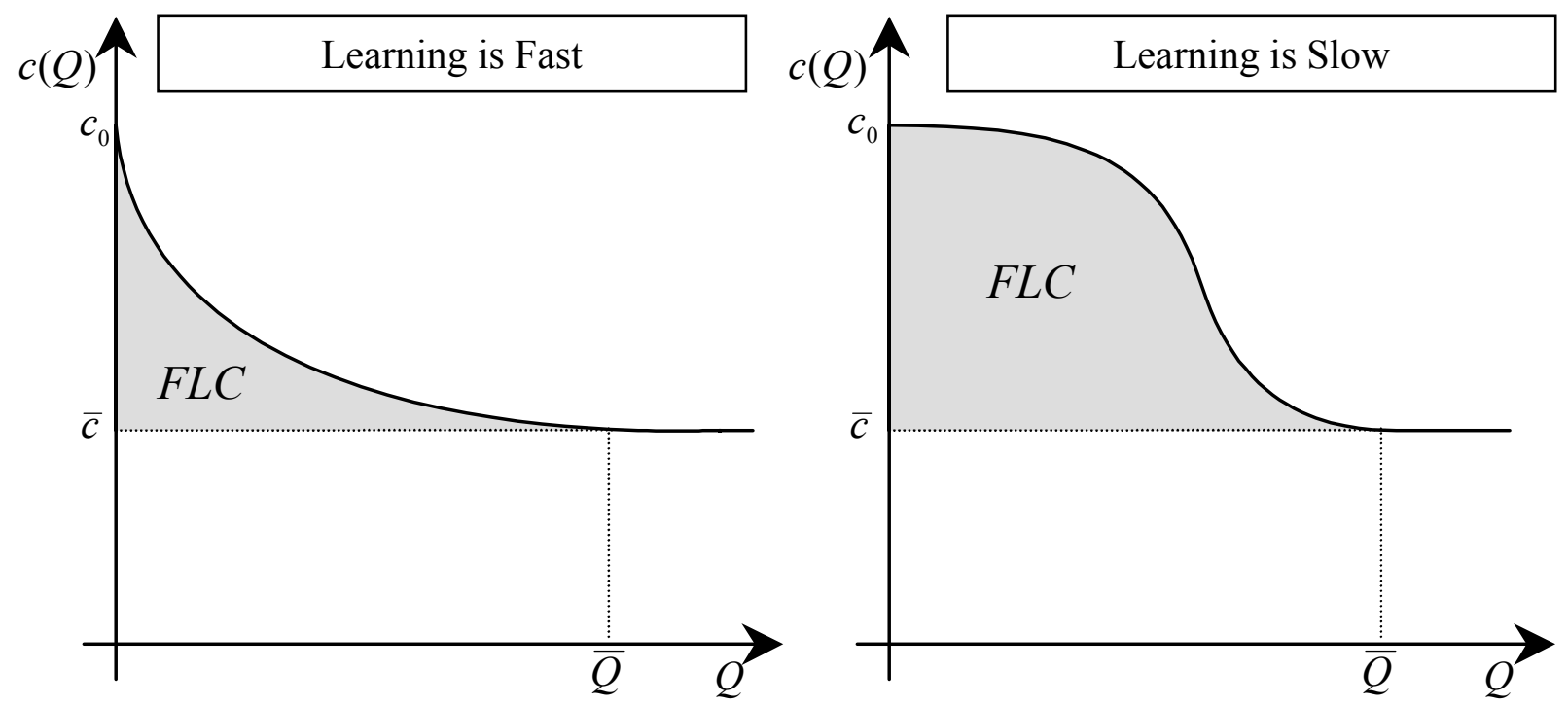

Figure 1: The Learning Curve and the Fixed Learning Cost

before the end of the planning period $\left(Q_{T} \geq \bar{Q}\right)$, yield a total welfare measure that can be written:

$$
\begin{aligned}
T W=\int_{0}^{T} W_{t} d t & =\int_{0}^{T}\left[U\left(q_{t}, \tilde{q}_{t}\right)-c\left(Q_{t}\right) q_{t}-\tilde{c} \tilde{q}_{t}\right] d t \\
& \left.=\int_{0}^{T}\left[U\left(q_{t}, \tilde{q}_{t}\right)-\bar{c} q_{t}-\tilde{c} \tilde{q}_{t}\right] d t-\int_{0}^{T}\left[c\left(Q_{t}\right)-\bar{c}\right) q_{t}\right] d t \\
& =\int_{0}^{T}\left[U\left(q_{t}, \tilde{q}_{t}\right)-\bar{c} q_{t}-\tilde{c} \tilde{q}_{t}\right] d t-\int_{0}^{\bar{Q}}\left[c\left(Q_{t}\right)-\bar{c}\right] d t
\end{aligned}
$$

Define a new welfare flow function $\bar{w}\left(q_{t}, \tilde{q}_{t}\right)=U\left(q_{t}, \tilde{q}_{t}\right)-\bar{c} q_{t}-\tilde{c} \tilde{q}_{t}$, which is the welfare flow assuming that the current domestic cost is constant at $\bar{c}$ instead of $c_{t}$. Further define the fixed learning cost $F L C$ as $\int_{0}^{\bar{Q}}([c(Q)-\bar{c}] d Q$. This cost is fixed because it does not depend on the chosen consumption paths but only on the learning function: it is the area below the learning curve above the lowest potential cost line at $\bar{c}$. Given $\bar{Q}$, and cost bounds $c_{0}$ and $\bar{c}, F L C$ will be determined by the "speed" of learning as shown in Figure 1.

Total welfare $T W$ can thus be written:

$$
T W=\int_{0}^{T} \bar{w}\left(q_{t}, \tilde{q}_{t}\right) d t-F L C
$$

Regardless of the chosen consumption paths $\left(q_{t}, \tilde{q}_{t}\right)$, the total welfare generated by these paths durpast the learning phase. The appendix shows how these effects can be included in the analysis without affecting the results. 
ing the planning period can be evaluated by using the static welfare flows $\bar{w}\left(q_{t}, \tilde{q}_{t}\right)$ and subtracting the same fixed cost $F L C$. This re-formulation allows a straightforward comparison of different trade policy scenarios: if the domestic industry does not produce, then the welfare flows are constant at $W^{0}=U\left(0, \tilde{q}^{0}\right)-\tilde{c} \tilde{q}^{0}=\bar{w}\left(0, \tilde{q}^{0}\right)$ and no fixed learning cost is incurred. ${ }^{17}$ If the domestic industry produces, then the same welfare function $\bar{w}\left(q_{t}, \tilde{q}_{t}\right)$ is used to evaluate the welfare flows and the fixed learning cost is subtracted. Given that learning occurs, the optimal trade policy ignores the learning cost and only seeks to maximize the cumulative welfare flows $\bar{w}\left(q_{t}, \tilde{q}_{t}\right)$. This helps to explain the optimal subsidy path that was previously derived under the assumption of negligible discounting: since $\bar{w}(.,$.$) is concave and attains its global maximum at (\bar{q}, \overline{\tilde{q}})$, the highest possible welfare flow is generated by keeping $q_{t}$ and $\tilde{q}_{t}$ constant at their long-run levels $\bar{q}$ and $\overline{\tilde{q}}$. These were precisely the optimal consumption paths induced by the optimal subsidies.

Let $\bar{W}=\bar{w}(\bar{q}, \overline{\tilde{q}})$ be the maximum value of the welfare flow function $\bar{w}(.,$.$) . The determination$ of the Mill-Bastable Test - that is, between subsidization and no protection (and no domestic industry) - thus depends on the weighing of the higher welfare flows $\bar{W} \geq W^{0}$ (the benefits of learning) against the fixed learning cost $F L C$. As the length of the planning horizon is extended, the subsidization alternative clearly becomes more attractive, because the benefits of the postlearning higher welfare are enjoyed over a longer time period. More interestingly, a low potential cost $\bar{c}$ does not automatically entail that subsidization is optimal: the low $\bar{c}$ can be offset by a high initial cost $c_{o}$ or a slow learning curve, which both increase the subsidization cost $F L C$ without affecting the difference between the welfare flows $\bar{W}$ and $W^{0}$. There will always exist a level of initial cost $c_{o}$ high enough and learning pace slow enough such that no subsidization is optimal even with arbitrarily low potential cost $\bar{c}$.

The degree of substitutability between the two goods also affects the relative merits of subsidization. In order to vary the degree of substitutability while ensuring positive demand for both goods under optimal subsidization, I assume that $\bar{c}=\tilde{c}$ (this is also a reasonable assumption that a common technology and factor price equalization will prevail in the long run and equalize costs). Then, as the products become closer substitutes, the difference between $\bar{W}$ and $W^{0}$ decreases and goes to zero as the goods become perfect substitutes. On the other hand, the learning cost $F L C$ does not change with the degree of substitutability. Assuming that subsidization is optimal if the goods are unrelated, the relative advantage of subsidization will then decrease with the level of product differentiation until the subsidization scenario is no longer optimal. Clearly, subsidization

\footnotetext{
${ }^{17}$ Recall that $\tilde{q}^{0}=\tilde{q}(p, \tilde{c})$ whenever $q(p, \tilde{c})=0$.
} 
will never be optimal when the goods are close enough substitutes, as the learning cost $F L C$ will always outweigh the small welfare advantage $\bar{W}-W^{0}{ }^{18}$ Interestingly, the degree of substitutability critically affects the fulfillment of the Mill-Bastable Test but has no effect on the optimal path of the subsidies, given that protection is optimal.

\section{Second Best Intervention: Subsidization no longer possible}

Given budgetary or political constraints, subsidies may become infeasible, leaving only tariffs or quotas as available instruments. ${ }^{19}$ The level of the tariff is still assumed (in this section) to be flexible over time. Tariffs and quotas therefore retain their equivalence. In the previous section, it was previously shown that production subsidies can raise welfare by raising production levels of the domestic good above their free-market levels. Tariffs obviously share some substitutability as policy instruments with the now unavailable subsidies since they can also raise domestic production levels. On the other hand, it is well known that tariffs also induce an extra distortion on the consumption side, creating a wedge between the marginal cost of the foreign good and its marginal benefit. The social planner must now trade off the benefits of higher domestic production against this new distortion. Further note that a very high initial cost $c_{0}$ may render tariffs useless as demand for the domestic good could still be zero in autarky (given arbitrarily high levels of tariffs).

\section{Interior Solution: Positive Domestic Production Levels}

The planner's maximization problem is still described by (1), but the set of feasible consumption pairs $\mathcal{F}_{t}$ is now restricted due to the infeasibility of subsidies. This restriction imposes marginal cost pricing of the domestic good, or $U_{q}\left(q_{t}, \tilde{q}_{t}\right)=c\left(Q_{t}\right)$, so long as positive quantities of the good are demanded. The consumption path of the foreign good is thus completely determined by the consumption path of the domestic good. The current value Hamiltonian $\mathcal{H}$ can be re-written as a function of only the domestic production level:

$$
\mathcal{H}\left(q_{t}, Q_{t}\right)=U\left(q_{t}, \tilde{q}_{t}\right)-c\left(Q_{t}\right) q_{t}-\tilde{c} \tilde{q}_{t}+\mu_{t} q_{t}
$$

\footnotetext{
${ }^{18}$ This still assumes that $\bar{c}=\tilde{c}$. If $\bar{c}$ is significantly below $\tilde{c}$, then subsidization may be optimal even when the two goods are perfect substitutes.

${ }^{19}$ Some of these constraints could also potentially alter the welfare function. This possibility is not considered in this paper.
} 
where $\tilde{q}_{t}$ is implicitly defined as a function of $q_{t}$ and $Q_{t}$ by $U_{q}\left(q_{t}, \tilde{q}_{t}\right)=c\left(Q_{t}\right)$ and $\mu_{t}$ is the new shadow price of cumulative domestic production. The new first order conditions are:

$$
\begin{aligned}
\frac{\partial \mathcal{H}}{\partial q_{t}} & =U_{q}\left(q_{t}, \tilde{q}_{t}\right)-c\left(Q_{t}\right)+\mu_{t}+U_{\tilde{q}}\left(q_{t}, \tilde{q}_{t}\right) \frac{\partial \tilde{q}_{t}}{\partial q_{t}}-\tilde{c} \frac{\partial \tilde{q}_{t}}{\partial q_{t}}=0, \\
\frac{\partial \mathcal{H}}{\partial Q_{t}} & =-c^{\prime}\left(Q_{t}\right) q_{t}+U_{\tilde{q}}\left(q_{t}, \tilde{q}_{t}\right) \frac{\partial \tilde{q}_{t}}{\partial Q_{t}}-\tilde{c} \frac{\partial \tilde{q}_{t}}{\partial Q_{t}}=\rho \mu_{t}-\dot{\mu}_{t}
\end{aligned}
$$

which can be re-written as

$$
\begin{gathered}
\tau_{t}=\frac{U_{q \tilde{q}}\left(q_{t}, \tilde{q}_{t}\right)}{U_{q q}\left(q_{t}, \tilde{q}_{t}\right)} \mu_{t}, \\
-c^{\prime}\left(Q_{t}\right) q_{t}+\frac{c^{\prime}\left(Q_{t}\right)}{U_{q q}\left(q_{t}, \tilde{q}_{t}\right)} \mu_{t}=\rho \mu_{t}-\dot{\mu}_{t} .
\end{gathered}
$$

(7) shows that tariffs do share some substitutability with the now unavailable subsidies and should be used to boost domestic production levels - so long as learning is not complete $\left(\mu_{t}>0\right)$ and the goods exhibit some substitutability $\left(U_{q \tilde{q}}(q, \tilde{q}) \neq 0\right)$. The equation of motion (8) now depends on the exact form of the substitution pattern between the goods. Therefore, in order to gain more insight on the optimal dynamic path of the tariff, the previously introduced demand parametrization is assumed. Recall that this linear demand system is characterized by two key parameters: $\beta$, the slope of the demand curves, and $\eta \in[0,1]$, the index of product substitutability. For additional simplicity, the assumption of negligible discounting is re-introduced.

Conditions (7) and (8) then yield:

$$
\begin{aligned}
\tau_{t} & =\eta \mu_{t} \\
& =\eta\left(c_{t}-\bar{c}\right)+\int_{t}^{\bar{t}} \frac{-c^{\prime}\left(Q_{t}\right)}{\beta} \tau_{s} d s
\end{aligned}
$$

where $\bar{t}$ is the endogenously determined time at which learning ceases. Naturally, the optimal tariffs depend on the level of product differentiation. Given the value of a unit of cumulative learning $\mu_{t}$ (which is bounded below by the learning potential $c_{t}-\bar{c}$ ), the optimal tariff response decreases with the level of product differentiation: tariffs are then increasingly ineffective tools for raising domestic production levels. (9) shows that, similarly to the case of subsidies, tariff protection should decrease as learning progresses and cease with learning when $c_{t}$ reaches $\bar{c}$. However, this optimal path for protection may not always be feasible: when the initial cost $c_{0}$ is high, the optimal path for domestic output could be infeasible as tariffs become ineffective once imports are driven 
to zero. In this case, tariff protection can not "save" the domestic industry. Reliance on imports under free trade must be the constrained (since subsidies are infeasible) welfare maximizing policy.

\section{The Mill-Bastable Test}

Free trade (no tariff protection) may also be the welfare maximizing policy in situations where protection could have been applied and led to the survival (and maturing) of the domestic industry $\left(\exists \tau, q\left(c_{0}, \tilde{c}+\tau\right)>0\right)$. This situation arises only when the domestic industry would not survive under free trade $\left(q\left(c_{0}, \tilde{c}\right)=0\right) .{ }^{20}$ As was the case with subsidies, the planner is then faced with a choice between protection (leading to the survival of the domestic industry) and laissez-faire (free trade and exclusive reliance on imports): the Mill-Bastable Test must be applied.

Assuming negligible discounting, the decomposition of total welfare under protection remains as in (6). The costs of protection, namely the fixed learning cost $F L C$, are thus identical to the case when subsidies were feasible. The benchmark welfare flows $W^{0}=\bar{w}\left(0, \tilde{q}^{0}\right)$ under no protection are also the same. The only difference involves the benefits of protection captured by the welfare flows $\bar{w}\left(q_{t}, \tilde{q}_{t}\right)$ during the planning period. Contrary to the case of subsidy protection, the global maximum of $\bar{w}(.,$.$) at \bar{W}=\bar{w}(\bar{q}, \overline{\tilde{q}})$ can not be reached until the domestic cost has reached its lower bound $\bar{c}$. This welfare difference reflects the additional consumption distortion introduced by tariff protection: production levels of the domestic good can only be raised via the distortion of the consumption decision for the foreign good. The optimal tariff path (9) is then chosen to maximize the cumulative welfare flows $\int_{0}^{T} \bar{w}\left(q_{t}, \tilde{q}_{t}\right) d t$ (since $F L C$ is independent of the chosen output paths). Given any domestic cost $c_{t}, \bar{w}\left(q_{t}, \tilde{q}_{t}\right)$ will be maximized at a tariff level $\tau=\eta\left(c_{t}-\bar{c}\right)$, and the difference between this maximized welfare level and $\bar{W}$ will decrease to zero as $c_{t}$ decreases to $\bar{c}$ (see appendix for proof). The optimal tariff (when positive) is therefore always above this level (as indicated by (9)) as it trades-off the per-period maximum of $\bar{w}\left(q_{t}, \tilde{q}_{t}\right)$ with the dynamic effects of higher current production, which allow future welfare flows to attain levels even closer to their maximum $\bar{W}$ (through the effect on lower future costs).

The difference between the higher total benefits under subsidy protection $(T \cdot \bar{W})$ and tariff protection is therefore a function of the speed of learning and the ability of tariffs to raise domestic production levels. This has two important consequences for the Mill-Bastable Test under tariff protection: i) the Mill-Bastable Test will fail (protection is not optimal) in cases where protection

\footnotetext{
${ }^{20}$ This is the only situation where both the optimal interior tariff path and free trade (no protection) satisfy the first order conditions for welfare maximization.
} 
via subsidies would satisfy the test. ii) The level of product differentiation now has an ambiguous effect on the result of the test. In contrast to the case of subsidies, higher levels of product differentiation no longer unambiguously make protection more appealing: they raise the potential benefits of a mature domestic industry but simultaneously render tariff protection less effective in boosting domestic production levels.

\section{$6 \quad$ Fixed Tariffs and Quotas}

In this section, I continue to assume that subsidization is infeasible. I further assume, due either to political constraints or to adjustment costs, that changing the level of a tariff or quota over time is costly. I initially assume that these costs are high enough that the social planner is constrained to pick only one tariff or quota level for the entire planning period. ${ }^{21}$ Although a quota is equivalent to a particular tariff level at any point in time, the value of this tariff level changes over time when the value of the quota remains fixed. A fixed quota and fixed tariff thus clearly have different dynamic properties, though both cases are subsumed in the previous section dealing with flexible tariffs.

Given these added restrictions on the use of trade instruments, the social planner must choose a trade instrument (quota or tariff), as well as determine its optimal level. Since this level remains fixed, these two choices completely determine the consumption paths throughout the entire planning period. The set of feasible consumption pairs $\mathcal{F}_{t}$ is thus reduced to a set of trajectories indexed by the choice of instrument and its level. Of course, the social planner can also choose not to protect the infant industry. In this case, the domestic industry would still produce (and learning would occur) if the initial cost were low enough $\left(q\left(c_{0}, \tilde{c}\right)>0\right)$. I initially assume this to be the case in order to eliminate the possibility of no domestic production and learning. No protection is then nested as a special case of a fixed tariff at zero (or high fixed quota level).

The previous analysis of the optimal flexible tariff highlights the intuition for the advantages of the quota over the tariff when their flexibility is restricted. A natural choice of quota level is the long run consumption level for the foreign good $\overline{\tilde{q}}$. This fixed quota generates a path over time for the equivalent tariff path that decreases throughout the learning period and remains at zero right after learning ceases: this is a good first approximation to the optimal flexible tariff path.

\footnotetext{
${ }^{21}$ This assumption on the large size of the adjustment cost is initially used for simplicity and will subsequently be relaxed. The qualitative results rely only on the presence of some non-negligible adjustment cost. The possibility of indexing the tariff to the current cost conditions is addressed in a later section.
} 
On the other hand, the problems with a fixed tariff are also clear: any fixed tariff either does not offer enough protection early in the learning phase, or protects too much towards the end of the learning phase. In fact, any positive fixed tariff necessarily protects too much after learning ceases when no protection is optimal. This tariff then induces consumption distortions from that point on, until the end of the planning period. These motivations for the superiority of the quota remain valid when discounting is introduced and for any type of utility function. However, for expositional simplicity, I maintain the assumptions of negligible discounting and linear demands - and show how a fixed quota then always dominates a fixed tariff.

Given that the domestic industry produces and learning occurs, the same fixed learning cost will be incurred and any two scenarios can be evaluated by comparing the accumulated welfare flows $\int_{0}^{T} \bar{w}\left(q_{t}, \tilde{q}_{t}\right) d t$ generated by each scenario. I first show that a fixed quota at $\overline{\tilde{q}}$ is indeed a reasonable choice: the welfare flows accumulated under this policy are higher at every point in time than those accumulated under any small fixed tariff (including the case of free trade). Although this comparison is not possible for some larger tariffs (this categorization of tariff size will be made explicit momentarily), it is then shown that the welfare flows under such a tariff are nevertheless dominated by a different fixed quota that is more restrictive than $\overline{\tilde{q}}$. The relative merits of this quota relative to $\overline{\tilde{q}}$ remain ambiguous. Nevertheless, the existence of a fixed quota that dominates any fixed tariff is guaranteed.

A tariff is labeled as small if it induces a learning period that is longer (or equal to) the learning period induced by the fixed quota at $\overline{\tilde{q}}$. This defines an upper bound tariff level. Any fixed tariff below this level generates welfare flows $\bar{w}\left(q_{t}, \tilde{q}_{t}\right)$ below those generated by the quota for the following reasons: given a domestic cost $c_{t}$, the tariff that maximizes $\bar{w}\left(q_{t}, \tilde{q}_{t}\right), \eta\left(c_{t}-\bar{c}\right)$, is precisely the tariff level induced by the quota at $\overline{\tilde{q}}$ (see appendix for proof). The welfare flow under the small tariff will be even further below this maximized level as the domestic cost will be above (or equal to) the cost under the quota at any point during the planning period. ${ }^{22}$

The preceding reasoning did not exclude the possibility of a high fixed tariff generating welfare flows above those generated by the quota at $\overline{\tilde{q}}$ in situations where the domestic cost under the tariff is significantly below the cost under the quota. Such a high fixed tariff would unlikely generate higher total welfare over the entire planning period since it would also entail very high levels of

\footnotetext{
${ }^{22}$ Consider the fixed tariff that induces the same learning period length as the quota set at $\overline{\tilde{q}}: Q_{t}$ reaches $\bar{Q}$ at the same time under both scenarios. The equivalent tariff generated by the quota must be above the fixed tariff level early on, and below it later on. This implies that cumulative production under the quota will be higher - and hence costs will be lower - at any given time. Any lower tariff will then generate even lower cumulative production levels and hence induce even higher costs.
} 
distortion later in the learning phase until the end of the planning period. However, in this unusual case, the high fixed tariff would still be dominated by a more restrictive fixed quota set below $\overline{\tilde{q}}$. In the appendix, it is shown that a fixed quota that generates a learning phase equal in length to that of an arbitrary fixed tariff always yields higher total welfare (both during the learning phase and after) than the tariff. ${ }^{23}$

\section{Small Adjustment Costs}

As the exogenous adjustment costs decrease, the social planner can consider changing the level of the trade instrument (tariff or quota) during the planning period. The latter would then be partitioned into smaller periods within which the trade instrument would be fixed. The number of partitions would increase as the adjustment costs fall. In the case of a tariff, the fixed tariff levels over each successive partition would decrease. The last partition would have a zero tariff and extend from the end of the learning phase to the end of the planning period. The number and timing of partitions along with their associated tariff levels would be endogenously determined by the planner as a function of the adjustment costs. In the limit, as the adjustment costs drop to zero, the time path of the optimal tariff will coincide with the optimal flexible tariff path that was previously derived.

In order to evaluate the choice of trade policy instruments, I assume that the adjustment costs depend only on the number of times the level of the trade instrument is changed. If the chosen trade instrument is a quota, then the optimal policy will similarly involve a partition of the planning period into segments with fixed quota levels. Although the number and timing of the partitions will be different than those chosen under the tariffs, it is nevertheless possible to compare total welfare levels under the two types of trade instruments. The quotas continue to dominate the tariffs, again yielding higher total welfare outcomes.

This dominance is driven by a simple consideration: given any individual partition of the planning period and any fixed tariff level within that partition, a fixed quota that generates the same amount of cumulative production as the tariff during this same partition must also yield higher total welfare over this period. ${ }^{24}$ Thus, the outcome of the optimal tariff policy can be easily compared to a quota policy that uses the same partitions and induces the same amount

\footnotetext{
${ }^{23}$ This is a special case of the proof used for the following section when welfare is evaluated over a subset of the learning phase. Welfare under the quota must be higher after learning ceases since the quota then generates an equivalent tariff that is lower than the fixed tariff level.

${ }^{24}$ See the appendix for a proof.
} 
of cumulative domestic production over each separate partition (the fixed quota levels over each partition are set in order to maintain this equality). This quota policy clearly dominates the optimal tariff policy as it yields higher total welfare in every partition while incurring the same amount of adjustment costs. ${ }^{25}$ The optimal quota policy will yield even further gains as the planner optimally chooses the number and timing of partitions for the quota.

\section{The Mill-Bastable Test}

When evaluating cases where the initial cost is high enough to preclude demand for the domestic good under free trade, then the option of no protection (and thus no domestic production) is potentially optimal. Once again, the social planner needs to trade-off the welfare flow benefits of protection against the fixed learning cost. These trade-offs are similar to the case of the flexible tariff, except that the welfare flow benefits will be lower as they are additionally constrained by the adjustment costs.

\section{Additional Advantages of the Quota}

When the high initial domestic cost precludes demand for the domestic good under no protection and the planning period extends significantly past the end of the learning phase, then the choice of protection with the fixed quota at $\overline{\tilde{q}}$ is clearly preferred to no protection: the fixed learning cost can be repaid, not only by higher welfare flows during the learning phase, but also by the welfare flows at the unrestricted maximum of $\bar{W}$ which accrue from the end of the learning phase until the end of the planning period. If the adjustment costs are also high and preclude changing the level of the trade instrument, then the fixed tariff offers a terrible alternative to the fixed quota: in order to induce initial production of the domestic good, the tariff must be set at a very high level comparable to the level of the initial equivalent tariff associated with the quota. Once learning progresses, this high tariff creates ever increasing distortions. When learning ceases, this high level of distortion (which generates a welfare flow far below $\bar{W}$ ) is maintained until the end of the planning period. This considerable difference between the welfare benefits of the quota and tariff could potentially outweigh any amount of revenue loss related to the administration of a quota. Thus, even a voluntary export restraint (assuming that the domestic country's transfer of revenue to foreign suppliers is not politically necessary to enact the restraint) could yield higher welfare

\footnotetext{
${ }^{25}$ The domestic cost at the beginning and end of every partition will be the same under both policies since the same amount of cumulative production occurs over each partition.
} 
gains to the domestic country than any fixed tariff alternative.

Although a fixed subsidy instrument is not formally modeled in this paper, it is also clearly possible for the fixed quota to yield higher welfare gains than an optimally chosen fixed subsidy. Even though the subsidy does not generate any consumption distortions for the foreign good (as do the quota and tariff), the rigidity of the subsidy nevertheless creates the same type of problems mentioned for the tariff: a fixed subsidy either does not protect the infant industry enough early in the learning phase, or it protects it too much later on.

Finally, the fixed quota exhibits one other advantage to policy makers over both the tariffs and subsidies, even when these are flexible: a lower information requirement for implementation. In order to calculate the long run consumption level of the foreign good $\overline{\tilde{q}}$ (and hence the optimal fixed quota), a policy maker only needs information on the foreign cost, the lower bound domestic cost, and demand conditions. In particular, no information on the shape of the learning curve (including its duration) is required. On the other hand, the setting of the optimal subsidies (when feasible) or tariffs, even when these instruments are flexible, requires detailed information on this learning curve. The learning curve may be known to firms and not the policy maker, in which case the firms would have strong incentives to distort any current and future cost information collected by the government. ${ }^{26}$ Furthermore, the learning curve may also have a stochastic element that is also unknown to firms. Although not formally modeled in this paper, the presence of such learning curve uncertainty can only reduce the effectiveness of the optimal subsidies or tariffs while it does not affect the performance of the optimal quota. ${ }^{27}$

\section{Conclusion}

This paper has focused on the practical considerations involved in policy decisions for infant industry protection. A policy maker first wants to make sure that a candidate industry only needs temporary protection and that this protection will generate higher cumulative benefits than costs. The paper shows how this Mill-Bastable Test can be re-formulated in a way that makes it easier to apply (when the effects of discounting are negligible): the cumulative costs can be approximated by a

\footnotetext{
${ }^{26}$ This problem was studied in Dinopoulos, Lewis and Sappington (1995). Their results show that the presence of asymmetric learning curve information between firms and the government may preclude protection that would have been optimal under symmetric information. In general, even asymmetric information about current costs (and not future costs) may prevent the government from enacting trade policies which would index the tariff or subsidy to the difference between current and lower bound cost.

${ }^{27} \mathrm{I}$ am assuming uncertainty about the shape and duration of the learning curve, and not uncertainty about the lower bound cost, which would affect the design of the optimal quota.
} 
fixed learning cost that only depends on the learning curve. If different policy instruments meet the conditions of the Mill-Bastable Test, the policy maker must then choose the optimal policy instrument for protection. The paper shows how limitations on the instrument's flexibility over time strongly affect this choice. Ideally, the policy maker wants to decrease the level of protection as learning progresses and eliminate protection once learning has ceased. Subsidies or tariffs need to be constantly lowered over time to produce this effect; these adjustments may not be feasible in practice. A fixed quota, on the other hand, automatically reduces its level of protection as domestic costs fall. The fixed quota can also be chosen so as to become non-binding once learning ceases. These characteristics endow the quota with advantages over the tariff and subsidy. Any uncertainty concerning the learning curve re-enforces these advantages.

The quota, however, also has some well known drawbacks vis-a-vis the tariff or subsidy. Quotas, even when their rights are auctioned, typically generate less revenue than comparable tariffs. They also, like tariffs, distort consumption decisions whereas domestic production subsidies do not. Finally, binding quotas eliminate some of the market discipline of tariffs when firms have market power. This paper does not intend to minimize these drawbacks but rather emphasizes the quota's particular advantages that specifically pertain to infant industry protection. The paper shows how, in this context, the advantages of the quota (especially over the tariff) are quite significant and could realistically outweigh these better known disadvantages. This paper does not intend to defend the use of quantity restrictions for infant industry protection as necessarily sound economic policy. Instead, this paper suggests that the use of some quantity restrictions may be less distorting than previously considered and that, in some specific cases, could have been the outcome of welfare maximizing behavior by the government. Furthermore, recommendations for future infant industry policies must also consider the problems that costly policy adjustments and learning curve uncertainty create for tariffs and subsidies. In certain cases, a policy maker will be confident that the industry's cost will drop over time but will be equally confident that any protection policy, once implemented, will be hard or impossible to repeal. In these cases, a quota will offer an attractive policy instrument that will ensure that the protection it provides will be temporary and will decrease in step with the domestic costs. 


\section{References}

Anderson, Simon P. and Nicolas Schmitt. 2003. "Nontariff Barriers and Trade Liberalization." Economic Inquiry 41:80-97.

Bagwell, Kyle and Robert W. Staiger. 1990. "A Theory of Managed Trade." American Economic Review 80:779-95.

Baldwin, Robert. 1969. "The Case Against Infant Industry Protection." Journal of Political Economy $77: 295-305$.

Bardhan, Pranab. 1971. "On the Optimum Subsidy to a Learning Industry: An Aspect of the Theory of Infant-Industry Protection." International Economic Review 12:54-70.

Bastable, Charles Francis. 1921. The Commerce of Nations. 10th ed. London: Macmillan and Co. Originally published in 1891.

Branstetter, Lee G. 2001. "Are knowledge spillovers international or intranational in scope? Microeconometric evidence from the U.S. and Japan." Journal of International Economics 53:53-79.

Clemhout, Simone and Henry Y Wan. 1970. "Learning-By-Doing and Infant Industry Protection." Review of Economic Studies 37:33-56.

Corden, W. Max. 1997. Trade Policy and Economic Welfare. 2nd ed. Clarendon Press.

Dasgupta, Partha and Joseph Stiglitz. 1988. "Learning-by-Doing, Market Structure and Industrial and Trade Policies." Oxford Economic Papers 40:246-268.

Deardorff, Alan. 1987. "Why Do Governments Prefer NonTariff Barriers." Carnegie-Rochester Conference Series on Public Policy 26:191-216.

Dinopoulos, Elias, Tracy Lewis and David Sappington. 1995. "Optimal Industrial Targeting with Unknown Learning-by-Doing." Journal of International Economics 38:275-295.

Dixit, Avinash. Supplement 1984. "Trade Policy for Oligopolistic Industries." Economic Journal 94:1-16.

Feenstra, Robert C. and Tracy R. Lewis. 1991. "Negotiated Trade Restrictions with Private Political Pressure." The Quarterly Journal of Economics 106:1287-307.

Head, Keith. 1994. "Infant Industry Protection in the Steel Rail Industry." Journal of International Economics 37:141-65.

Irwin, Doug. 2000. "Did Late-Nineteenth-Century U.S. Tariffs Promote Infant Industries? Evidence from the Tinplate Industry." The Journal of Economic History 60:335-60.

Kemp, Murray C. 1960. "The Mill-Bastable Infant Industry Dogma." Journal of Political Economy 68:65-67.

Krugman, Paul. 1987. "The Narrow Moving Band, the Dutch Disease, and the Competitive Consequences of Mrs. Thatcher." Journal of Development Economics 27:41-55.

Mill, John Stuart. 1848. Principles of Political Economy. In Collected Works of John Stuart Mill, ed. J. M. Robson. Vol. III University of Toronto Press pp. 918-19. 
Redding, Stephen. 1999. "Dynamic Comparative Advantage and the Welfare Effects of Trade." Oxford Economic Papers 51:15-39.

Succar, Patricia. 1987. "The Need for Industrial Policy in LDC's - A Re-Statement of the Infant Industry Argument." International Economic Review 28:521-534.

Young, Alwyn. 1991. "Learning by Doing and the Dynamic Effects of International Trade." The Quarterly Journal of Economics 106:369-405. 


\section{Appendix}

\section{Properties of the welfare flow function $\bar{w}\left(q_{t}, \tilde{q}_{t}\right)$}

Let $\tau^{*}\left(c_{t}\right)$ be the tariff level that maximizes the welfare flow $\bar{w}\left(q_{t}, \tilde{q}_{t}\right)$ when subsidies are infeasible. This tariff is therefore the maximand of $\bar{w}\left[q\left(c_{t}, \tilde{c}+\tau\right), \tilde{q}\left(c_{t}, \tilde{c}+\tau\right)\right]$. The first order condition for an interior solution to this problem is

$$
\left(c_{t}-\bar{c}\right) \frac{\partial q\left(c_{t}, \tilde{c}+\tau\right)}{\partial \tau}+\tau \frac{\partial \tilde{q}\left(c_{t}, \tilde{c}+\tau\right)}{\partial \tau}=0
$$

Under the linear demand structure $\left(\right.$ where $\left.U_{q \tilde{q}}(q, \tilde{q}) / U_{\tilde{q} \tilde{q}}(q, \tilde{q})=[\partial q(p, \tilde{p}) / \partial \tilde{p}] /[\partial \tilde{q}(p, \tilde{p}) / \partial \tilde{p}]=\eta\right)$, the welfare maximizing tariff is therefore given by $\tau^{*}\left(c_{t}\right)=\eta\left(c_{t}-\bar{c}\right)$. This tariff level, in turn, is equivalent to a quota set at $\overline{\tilde{q}}$ since

$$
\begin{aligned}
\tilde{q}\left[c_{t}, \tilde{c}+\eta\left(c_{t}-\bar{c}\right)\right] & =\tilde{q}(\bar{c}, \tilde{c})+\eta \beta\left(c_{t}-\bar{c}\right)+\beta \tau \\
& =\tilde{q}(\bar{c}, \tilde{c})
\end{aligned}
$$

By the envelope theorem, the maximized value of $\bar{w}(.,$.$) obtained under the quota at \overline{\tilde{q}}$ must increase as $c_{t}$ decreases, reaching its global maximum at $\bar{W}=\bar{w}(\bar{q}, \bar{q})$ when $c_{t}$ reaches its lower bound $\bar{c}$.

\section{Comparing Fixed Tariffs and Quotas Over Any Partition of the Planning Period}

Consider any fixed tariff level over any given partition of the planning period extending from $t_{1}$ to $t_{2}$. Cumulative production is initially at $Q_{1}$ at time $t_{1}$ and increases to $Q_{2}$ at $t_{2}$. Assuming negligible discounting, total welfare over this partition can be decomposed in the following way:

$$
\begin{aligned}
T W=\int_{t_{1}}^{t_{2}} W_{t} d t & =\int_{t_{1}}^{t_{2}}\left[U\left(q_{t}, \tilde{q}_{t}\right)-\hat{c} q_{t}-\tilde{c} \tilde{q}_{t}\right] d t-\int_{Q_{1}}^{Q_{2}}[c(Q)-\hat{c}] d Q \\
& =\int_{t_{1}}^{t_{2}} \hat{w}\left(q_{t}, \tilde{q}_{t}\right) d t-\widehat{F L C},
\end{aligned}
$$

where $\hat{w}\left(q_{t}, \tilde{q}_{t}\right)=U\left(q_{t}, \tilde{q}_{t}\right)-\hat{c} q_{t}-\tilde{c} \tilde{q}_{t}$ and $\hat{c}$ is any arbitrary cost level. This decomposition will be valid for any consumption paths that induce the same level of cumulative domestic production during this partition (such that $Q_{t_{2}}=Q_{2}$ ). The difference in total welfare generated by any two such paths will then be given by the cumulative difference in the welfare flows $\hat{w}\left(q_{t}, \tilde{q}_{t}\right)$.

Now consider a fixed quota that generates the same level of cumulative domestic production 
during the partition (such that $Q_{t_{2}}=Q_{2}$ under the quota). Further pick $\hat{c}$ such that $\tilde{q}(\hat{c}, \tilde{c})$ is equal to this quota level. Then, given $c_{t}, \hat{w}\left[q\left(c_{t}, \tilde{c}+\tau\right), \tilde{q}\left(c_{t}, \tilde{c}+\tau\right)\right]$ is maximized when $\tau=\eta\left(c_{t}-\hat{c}\right)$; this is precisely the tariff level generated by the quota (the reasoning is identical to the one developed in the previous section). The welfare flow $\hat{w}(.,$.$) at any point in time during the partition must$ therefore be higher under the quota than under the tariff. Since the domestic cost $c_{t}$ is always higher under the tariff (see footnote 22). Hence, a fixed tariff is always dominated by a fixed quota that induces the same amount of cumulative domestic production during the partition. 


\section{Supplemental Appendix:}

\section{The Effects of Discounting on Total Welfare Comparisons}

Some derivations in the paper assumed a negligible discount rate in order to simplify the comparison of total welfare levels under different policy scenarios. Given any of the policy instrument restrictions considered in the paper, an increase in the exogenous discount rate will affect the optimal protection levels by making protection less valuable. ${ }^{1}$ On the other hand, any reasonably low discount rate will not qualitatively affect the total welfare comparisons derived in the paper.

When the effects of discounting are explicitly modeled, total welfare $T W$ over the planning period can still be decomposed into the accumulated welfare flows $\bar{W}$ and the fixed learning cost $F L C$ in the following way:

$$
\begin{aligned}
T W & =\int_{0}^{T} e^{-\rho t} W_{t} d t \\
& \left.=\int_{0}^{T} e^{-\rho t}\left[U\left(q_{t}, \tilde{q}_{t}\right)-\bar{c} q_{t}-\tilde{c} \tilde{q}_{t}\right] d t-\int_{0}^{T} e^{-\rho t}\left[c\left(Q_{t}\right)-\bar{c}\right) q_{t}\right] d t \\
& =\int_{0}^{T} e^{-\rho t}\left[U\left(q_{t}, \tilde{q}_{t}\right)-\bar{c} q_{t}-\tilde{c} \tilde{q}_{t}\right] d t-\alpha \int_{0}^{\bar{Q}}\left[c\left(Q_{t}\right)-\bar{c}\right] d t . \\
& =\int_{0}^{T} e^{-\rho t} \bar{w}\left(q_{t}, \tilde{q}_{t}\right) d t-\alpha \cdot F L C
\end{aligned}
$$

where $\left(q_{t}, \tilde{q}_{t}\right)$ is any consumption path such that learning occurs and ends at a time $\bar{t}$ before the end of the planning period $T$, and $\alpha$ is some number between $e^{-\rho t}$ and $1 .^{2}$ Similarly, when the domestic good is not produced, total welfare would then be written:

$$
T W^{0}=\int_{0}^{T} e^{-\rho t} \bar{w}\left(0, \tilde{q}^{0}\right) d t=\int_{0}^{T} e^{-\rho t} W^{0} d t .
$$

\section{Optimal Protection Versus No Protection}

Given a positive level of domestic production, let $\left(q_{t}^{*}, \tilde{q}_{t}^{*}\right)$ be the optimal consumption paths under protection (the trade instruments used to protect may be restricted in the ways previously discussed.) The decision to protect the domestic industry then depends on the comparison of the total welfare levels $T W^{*}=\int_{0}^{T} e^{-\rho t} \bar{w}\left(q_{t}^{*}, \tilde{q}_{t}^{*}\right) d t-\alpha \cdot F L C$ and $T W^{0}=\int_{0}^{T} e^{-\rho t} W^{0} d t$. Higher welfare flows $\bar{w}\left(q_{t}^{*}, \tilde{q}_{t}^{*}\right) \geq W^{0}$ must again be weighed against the learning cost $\alpha \cdot F L C$.

\footnotetext{
${ }^{1}$ As the discount rate approaches infinity, no protection would always be optimal.

${ }^{2} \alpha$ will depend on both the discount rate $\rho$ and the consumption paths $\left(q_{t}, \tilde{q}_{t}\right)$.
} 
Comparative statics involving the level of product differentiation will affect the difference between $\bar{w}\left(q_{t}^{*}, \tilde{q}_{t}^{*}\right)$ and $W^{0}$ in the same way as was previously derived. Since this comparison involves the flows at each point in time, the discounting of these flows will not affect the comparisons. Similarly, comparative statics involving the shape of the learning curve will affect $F L C$ in an identical way as was previously derived. The only problem will be that these comparative statics will also affect the level of $\alpha$. Given a small discount rate and a relatively short learning phase, this change in $\alpha$ will be dominated by the changes in the welfare flows or the learning cost $F L C$. Thus, the effects of product differentiation, the length of the planning period, cost bounds, and shape of the learning curve on the choice to protect the infant industry will remain unchanged under any reasonable discounting.

\section{Fixed Tariff Versus Fixed Quota}

In the paper, it was shown that given certain conditions on the shape of the utility function and the

shape of the learning curve, the welfare flow $\bar{w}\left(q_{t}, \tilde{q}_{t}\right)$ generated by the fixed quota at $\overline{\tilde{q}}$ is always higher than the welfare flow generated by any fixed tariff. The discounting of these flows in the total welfare computation will not affect the total welfare ranking of the quota and tariff: later differences in the flows will just count less than earlier differences, but these differences will still always have the same sign favoring the quota. On the other hand, the values of $\alpha$ entering into the total welfare computation will now be slightly different under the quota and the tariff. The learning cost $\alpha \cdot F L C$ under the two instruments will no longer be identical and will not cancel each other out in the total welfare comparisons. Again, these changes in $\alpha$ will be small and will be dominated by the difference in the welfare flows. The comparison of total welfare under the two instruments will be very unlikely to be reversed by the inclusion of these discounting effects. 